\title{
Freqüência e uso de estrangeirismos ingleses no português brasileiro: Um estudo baseado em corpus
}

\author{
Tony Berber Sardinha* \\ Leila Barbara** \\ PUC SP
}

Neste trabalho, apresentamos uma investigação baseada em corpora acerca da extensão do uso de estrangeirismos de origem inglesa no português do Brasil. Para tanto, utilizamos o corpus Banco de Português, do projeto DIRECT (LAEL, PUCSP), com mais de 230 milhões de palavras, de fontes orais e escritas, e o British National Corpus, com cerca de 100 milhões de palavras, também provenientes da escrita e fala. A investigação motiva-se (1) pela necessidade do envolvimento dos lingüistas e lingüistas aplicados em debates acerca de políticas públicas, (2) por ser esse um tema caro ao prof. John Robert Schmitz, e (3) pela escassez de trabalhos sobre estrangeirismos que utilizem corpora eletrônicos. Os resultados indicam que (1) há muitos anglicismos em vigor no português brasileiro, (2) a freqüência deles é baixa e (3) eles parecem adquirir sentidos e usos diferentes da língua de origem.

In this paper, we report a corpus-based investigation on the spread of use of English words in Brazilian Portuguese. For this purpose, we employed the Bank of Portuguese, a corpus created by the DIRECT Project (LAEL, PUC/ SP), with over 230 million words, from spoken and written sources, and the British National Corpus, with 100 million words, from writing and speech as well. Our research is motivated by the following points: (1) the need for the engagement of linguists and applied linguists in debates over public policies, (2) the fact that this is a theme pursued by John Robert Schmitz, and (3) the lack of studies on foreign word borrowings based on electronic corpora. Results suggest that (1) a large number of English words are in use in Brazilian Portuguese, (2) their frequency is low, and (3) these words take on new different meanings from English.

* O autor agradece ao CNPq pelo auxílio 350455/2003-1.

" A autora agradece ao CNPq pelo auxílio 500945/2003-9. 


\section{Introdução}

Recentemente, muitos lingüistas e lingüistas aplicados sentiramse impelidos a tomar parte em um debate que abarcou a sociedade: a questão dos estrangeirismos. Esses são entendidos como "palavras e expressões de outras línguas, usadas correntemente em algumas áreas do nosso cotidiano" (FARACO, 2001, p. 9). No âmbito desse debate, assistimos a vários profissionais e cientistas de linguagem conclamando seus pares a se pronunciarem diante do projeto de lei no 1676/99 do deputado Aldo Rebelo, que pretende "proteger" a língua portuguesa de uma suposta "ameaça" de "invasão" de palavras de origem estrangeira (mais especificamente, oriundas do inglês).

Neste trabalho, deixaremos de lado a definição própria de "palavra portuguesa", tendo em vista as dificuldades em se delimitar claramente o que vem a ser uma palavra genuinamente portuguesa. Note que até mesmo a instância indicada pelo projeto de lei como sendo a autoridade máxima da língua, a Academia Brasileira de Letras, inclui estrangeirismos no Vocabulário Ortográfico da língua portuguesa. Um desses é "site", que lá consta como "site (saite) s.m. ing.". Vale notar que "site" é visto assim por alguns: "Da avalancha de expressões inglesas que deformam a língua portuguesa, uma, em particular, é humilhante: site.” (http:// www.igutenberg.org/jj29idioma.html). Por isso, partiremos para uma abordagem baseada em corpus, isto é, em instâncias de uso da língua (vide abaixo). A própria Academia admite que

O certo é que a língua portuguesa cresceu, até mesmo em virtude da introjeção de termos ligados ao desenvolvimento científico e tecnológico ou de muitos estrangeirismos. É o caso de palavras como teleducação (educação à distância), acessar (entrar), deletar (apagar, anular), decassegui (trabalhador brasileiro no Japão), teleconferência (conferência à distância), lincar (ligar), internet, infovia, intranet, etc. (http://www.academia.org.br/ortogra.htm).

No nosso caso, quando nos referirmos a estrangeirismos, estaremos fazendo alusão a palavras existentes na língua inglesa. Tampouco nos aventuraremos no campo teórico, tentando definir o que é ser uma palavra inglesa. Basta lembrar que o inglês contemporâneo possui uma presença massiva de palavras de origem latina para dar-nos conta das dificuldades inerentes de uma tentativa nesse sentido. 
A posição do lingüista aplicado na sociedade é a de estabelecer um debate corrente, com muitas e sérias implicações. Tomar posição nele é, portanto, uma atitude política (RAJAGOPALAN, 2003). A sociedade conclama os "cientistas da linguagem" a se pronunciarem a respeito desse tema, que pode afetar a vida das pessoas de várias maneiras, além de sinalizar um entendimento legal a respeito de como deveria ser a língua dos brasileiros.

Um desses cientistas de linguagem que jamais se furtou a participar dos debates públicos envolvendo questões lingüísticas nacionais é John Robert Schmitz. No referido debate em torno dos estrangeirismos, lá vemos John falando e escrevendo publicamente a partir do ponto de vista da lingüística aplicada e da lexicografia (SCHMITZ, 1999, 2000a, b, 2001a, b, 2002). Em outro, envolvendo ataques à Lingüística Aplicada por parte de um grande nome de um ramo da lingüística formal, também lá estava o Prof. John (SCHMITZ, 2004). Aliás, cabe lembrar que muito antes do referido projeto de lei, John já escrevia sobre o assunto (SCHMITZ, 1988). Por conta desse envolvimento, sofreu várias críticas (JORGE, 2002), acendendo outro debate (CUNHA, 2002).

Neste trabalho, desejamos fazer uma contribuição ao debate sobre os estrangeirismos na língua portuguesa a partir da Lingüística de Corpus, que é um ramo da lingüística voltado ao estudo da linguagem por meio de corpora eletrônicos, isto é, coletâneas de amostras de língua falada e escrita armazenadas e manuseadas por computador (BERBER SARDINHA, 2004; BIBER, CONRAD \& REPPEN, 1998). Mais especificamente, trazemos evidências a respeito da quantidade de palavras inglesas na língua portuguesa e de seus usos em comparação com o emprego das mesmas palavras na língua inglesa. Investigações sobre a presença e freqüência de estrangeirismos no português brasileiro ainda são escassas (ALVES \& MARONEZE, 2003; BERBER SARDINHA, 2004, p. 177-184). Entretanto, elas podem identificar com mais clareza e exatidão a verdadeira extensão da chamada "ameaça" dos estrangeirismos.

Um dos lingüistas aplicados que nos insta a buscar respostas em corpora é o próprio John Schmitz. Ele lança questões que somente podem ser respondidas por meio de freqüências extraídas de corpus eletrônico. Por exemplo, em relação à palavra "printar", ele indaga: "será que ocorre livremente em textos?” (SCHMITZ, 2001b, p. 92). Ele resume, no mesmo trabalho, uma posição chave que pretendemos avançar neste trabalho: "Seria de grande utilidade, sem dúvida, identificar os estrangeirismos e sua freqüência” (ibid, p. 99). Outros lingüistas também colocam 
questões ou posições acerca da freqüência de estrangeirismos que poderiam ser iluminadas com o uso de corpora. Por exemplo, Bagno (2001, p. 81) pergunta se "haveríamos de temer que um punhado de palavras de origem inglesa poderia ser "lesivo" ou "descaracterizar" a língua portuguesa falada no Brasil". Com contagens baseadas em corpora extensos, poderíamos saber várias coisas acerca desse punhado, como seu tamanho, composição, e até mesmo se é um punhado ou uma "avalancha".

Além disso, com apoio em corpora, poderemos evitar recorrer à intuição sobre como seria a língua portuguesa para vê-la como seus falantes realmente a empregam, pois "uma abordagem intuitiva dos fatos lingüísticos [é] quase sempre baseada em mitos, superstições e aparências enganadoras" (BAGNO, 2001, p. 73). Precisamos salientar a importância de que o corpus seja eletrônico. Conforme já enfatizado pelos lingüistas de corpus (MCENERY \& WILSON, 1996; SINCLAIR, 1991), um corpus eletrônico torna a pesquisa não somente mais confiável, como também mais apta a revelar aspectos que desconhe-cíamos a respeito da língua. Assim, por ser eletrônico, usaremos programas de computador especializados para buscar, contar e comparar ocorrências de palavras. Esses procedimentos se distinguem do tipo de análise com corpus que preconiza uma leitura feita "com lápis na mão para ir assinalando cada ocorrência" (BAGNO, 2001, p. 77).

Desejamos rever, à luz da evidência advinda de corpora, dois pressupostos básicos dos simpatizantes do projeto de lei 1676/99, quais sejam:

(a) Haveria uma invasão de palavras estrangeiras na língua portuguesa, particularmente de origem anglo-saxã.

(b) As palavras estrangeiras não se adaptariam ao português.

\section{Corpora empregados na pesquisa}

Os corpora empregados na pesquisa foram os seguintes:

\begin{tabular}{|l|l|l|}
\hline Variedade & Corpus & Palavras (tokens) \\
\hline Inglês britânico & BNC (British National Corpus) & 100.602 .129 \\
\hline Português brasileiro & Banco de Português & 231.960 .832 \\
\hline
\end{tabular}

Tabela 1: Descrição dos corpora 
O British National Corpus é uma referência entre os corpora de língua inglesa. Ele é fechado, isto é, sua composição é imutável, e é formado por textos orais e escritos de procedência britânica (em sua quase totalidade). Esse corpus é comercializado por um consórcio de editoras e universidades.

O Banco de Português é um corpus aberto, cujo conteúdo é constantemente atualizado. Ele contém textos orais e escritos (em sua maioria jornalísticos), quase inteiramente de origem brasileira. Todos os textos e transcrições contidos nele são de circulação brasileira, mesmo que não tenham sido escritos ou falados por autores falantes nativos do português brasileiro. O Banco de Português é armazenado na Pontifícia Universidade Católica de São Paulo, sendo fruto do projeto DIRECT. Para mais informações sobre o BP, favor consultar o website do corpus, em http://lael.pucsp.br/corpora/bp, onde estão disponíveis ferramentas para exploração do corpus, além de acesso aos textos integrais.

Os instrumentos usados na análise dos corpora foram:

- WordSmith Tools (SCOTT, 1998): Listador de freqüências, concordanciador.

- Programas específicos: Rotinas criadas especialmente para esta pesquisa por um dos autores, usando Text Utilities e outros utilitários do sistema operacional Unix.

- Calculador de Mutual Information e T-Score (BERBER SARDINHA, 2003): Programa disponível online, em http://lael.pucsp.br/corpora, que efetua o cálculo de estatísticas de associação (mais detalhes abaixo).

\section{Quantidade de palavras inglesas no português brasileiro}

Nesta parte do artigo, faremos uma incursão nos corpora de estudo com vistas a revisitar o primeiro dos pressupostos elencados acima, qual seja, o de que há uma invasão de palavras estrangeiras (de origem inglesa) no português do Brasil.

A tabela 2 traz o resultado da comparação dos dois corpora (Banco de Português e BNC), feita item a item, para saber quantas palavras ${ }^{1}$ (types) as duas línguas possuem em comum.

\footnotetext{
${ }^{1}$ É importante lembrar que foram comparadas as formas ortográficas das palavras e não seus sentidos. Assim, uma palavra como 'a' é comum ao português e ao inglês, mas possui significados diferentes em cada uma.
} 


\begin{tabular}{|l|c|}
\hline & $\begin{array}{l}\text { Palavras diferentes } \\
\text { (types) }\end{array}$ \\
\hline Português total & 618.868 \\
\hline Inglês total & 385.750 \\
\hline Palavras em comum & 100.172 \\
\hline
\end{tabular}

Tabela 2: Porcentagem de palavras comuns aos dois corpora

Como se percebe, há cerca de 100 mil palavras em comum entre os dois corpora. Em termos do corpus de português, isso corresponde a 16,10\%, ou aproximadamente uma palavra a cada seis. ${ }^{2}$ A tabela 3 a seguir traz os números relativos a cada corpus.

\begin{tabular}{|l|l|l|}
\hline Língua & Itens não compartilhados & $\%$ do total \\
\hline Português & 518.696 & $84 \%$ \\
\hline Inglês & 285.578 & $74 \%$ \\
\hline
\end{tabular}

Tabela 3: Número e porcentagem de itens diferentes em cada língua

Quando comparamos os dois corpora não por completo, mas em faixas de freqüência, descobrimos que o grau de compartilhamento decresce rapidamente.

\begin{tabular}{|l|l|l|}
\hline $\begin{array}{l}\text { Palavras em comum } \\
\text { entre as ... }\end{array}$ & $\begin{array}{l}\text { Palavras } \\
\text { (tokens) }\end{array}$ & $\begin{array}{l}\% \text { (do total } \\
\text { do português) }\end{array}$ \\
\hline 50 mil mais freqüentes & 6.998 & $1,13 \%$ \\
\hline 10 mil mais freqüentes & 672 & $0,11 \%$ \\
\hline
\end{tabular}

Tabela 4: Porcentagem de palavras em comum em dois tipos de freqüência

Entre as 50 mil palavras mais freqüentes (o que significa palavras com freqüência em torno de 120, isto é, de 1 vez a cada 2 milhões de palavras), as palavras em comum são apenas cerca de 1\% do total. Indo para freqüências mais altas, na faixa das 10 mil palavras mais freqüentes, que ocorrem cerca de 1700 vezes no Banco de Português (ou 7 vezes por milhão), as palavras em comum correspondem a apenas 1 décimo de 1 por cento. Isso significa que os estrangeirismos, ao contrário do que se diz, não são freqüentes na língua portuguesa.

\footnotetext{
${ }^{2}$ Em relação ao total de itens (types).
} 
Conforme mostrado acima, $74 \%$ das palavras em uso no inglês não estão presentes no português. Dito de outro modo, $26 \%$ do vocabulário que está em uso no inglês também está na língua portuguesa. Isso pode parecer bastante alarmante, mas é preciso lembrar que essa é uma via de mão dupla: estamos contando as palavras em comum, sem distinção de sua origem. Vale lembrar que boa parte do vocabulário inglês é de origem latina, assim como no português. Visto por esse lado, não é de se espantar esse grau de compartilhamento.

Determinar a etimologia das palavras compartilhadas foge ao propósito deste trabalho. No entanto, uma indicação inicial da origem dessas palavras pode ser obtida por meio da presença de letras banidas do nosso alfabeto oficial: k, w e y, além de seqüências de caracteres típicas do inglês, como "tion", "ing" e "s". Contando as palavras que possuem tais letras e seqüências entre as palavras em comum, obtivemos um total de 6311, isto é, cerca de $94 \%$ do total de palavras compartilhadas. Esses números sugerem que entre as palavras compartilhadas figuram, maciçamente, palavras com grafia inglesa. Em conclusão, isso indica que as palavras compartilhadas entre as duas línguas se parecem mais com o inglês do que com o português. Sendo assim, a origem imediata mais provável do vocabulário em comum é o inglês.

Entre as seis mil palavras que não possuem tais traços característicos da grafia inglesa, estão, quase sempre, nomes próprios e siglas, como por exemplo:

\begin{tabular}{|l|l|l|}
\hline ABDUL & BRUM & FERRARA \\
ABDULAH & BUA & JARRELL \\
ABE & BUARQUE & JAVA \\
ABEF & CPD & JAZZ \\
ABEL & CPH & RUDER \\
BRUDER & CPL & RUEFF \\
BRUEL & CPM & ZUMA \\
BRUER & FERBER & ZURCHER \\
BRUHL & FERMER & ZVEZDA \\
BRULÉE & FERMÉ & \\
\hline
\end{tabular}

Notamos que entre essas estão palavras com grafia alemã, francesa e italiana. Dado que são nomes próprios, uma das coisas que revelam, em certa medida, é o grau de "miscigenação" dos povos, provavelmente ocasionado pela imigração, tanto no Brasil quanto nos EUA. 


\section{Uma palavra estrangeira em uso no português: marketing}

Dentre as várias palavras comuns ao português e ao inglês que possuem grafia inglesa está marketing. Essa é uma palavra freqüente tanto no português quanto no inglês, conforme mostra a tabela a seguir:

\begin{tabular}{|l|l|l|l|}
\hline Língua & Freqüência & \% do total & Posição \\
\hline Português & 17.113 & 0,007 & 1461 \\
\hline Inglês & 5.021 & 0,005 & 1986 \\
\hline
\end{tabular}

Tabela 5: Freqüência da palavra marketing nos dois corpora

Como se percebe, marketing é mais comum no português do que no inglês. Por sua alta freqüência e por sua grafia, essa se torna uma palavra indicada para se verificar até que ponto uma palavra estrangeira incorpora-se ao português.

A fim de conhecermos o uso dessa palavra no corpus, aplicamos o conceito de padrão (pattern), conforme usado na Lingüística de Corpus. Padrão é a fraseologia mais típica de uma palavra, representada por suas colocações, coligações e prosódia semântica mais freqüentes (BERBER SARDINHA, 2004, p. 31). Para detectar a padronização das palavras, extraímos seu conjunto de colocados (palavras que aparecem próximas) e fizemos uma estimativa do grau de associação entre essa palavra e seus colocados. As concordâncias e os colocados foram obtidos com o programa WordSmith Tools (SCOTT, 1998).

O grau de associação foi medido por duas estatísticas: Mutual Information e T-Score (BERBER SARDINHA, 2004, p. 200-205). Conforme dito acima, o cálculo foi realizado com a ferramenta "Analisador de Tabela de Colocados", disponibilizada online na página de ferramentas de análise de corpus do CEPRIL/LAEL (vide anexos para reproduções parciais dos resultados fornecidos pelo programa).

Os principais colocados de marketing no corpus de português, ordenados pelo valor de Mutual Information, são os seguintes: 


\begin{tabular}{|c|c|c|c|c|c|}
\hline & Colocado & $f_{c}$ & fnc & MI & T-Score \\
\hline 1 & QUINZENAL & 305 & 91 & 10.396 & 9.532 \\
\hline 2 & PALESTRANTE & 527 & 137 & 10.202 & 11.695 \\
\hline 3 & ARENA & 3971 & 535 & 9.250 & 23.092 \\
\hline 4 & SPORTS & 1158 & 151 & 9.202 & 12.267 \\
\hline 5 & TRAFFIC & 1038 & 74 & 8.331 & 8.576 \\
\hline 6 & GERENTE & 18743 & 1262 & 8.247 & 35.408 \\
\hline 7 & CICLO & 9196 & 436 & 7.742 & 20.783 \\
\hline 8 & ESTRATÉGIAS & 4182 & 163 & 7.460 & 12.694 \\
\hline 9 & JOGADA & 5123 & 163 & 7.167 & 12.678 \\
\hline 10 & RELACIONADAS & 2710 & 75 & 6.966 & 8.591 \\
\hline 11 & PROPAGANDA & 15915 & 401 & 6.829 & 19.850 \\
\hline 12 & ISL & 2132 & 52 & 6.783 & 7.145 \\
\hline 13 & PUBLICIDADE & 12612 & 305 & 6.770 & 17.304 \\
\hline 14 & ESTRATÉGIA & 19383 & 468 & 6.769 & 21.435 \\
\hline 15 & DIRETORA & 11765 & 223 & 6.419 & 14.759 \\
\hline 16 & PALESTRA & 7884 & 147 & 6.395 & 11.980 \\
\hline 17 & DIRETOR & 103362 & 1508 & 6.042 & 38.244 \\
\hline 18 & CONSULTOR & 7154 & 103 & 6.023 & 9.993 \\
\hline 19 & PELÉ & 12892 & 148 & 5.695 & 11.931 \\
\hline 20 & VENDAS & 37570 & 428 & 5.685 & 20.286 \\
\hline 21 & COMUNICAÇÃO & 25069 & 273 & 5.619 & 16.187 \\
\hline 22 & ASSISTENTE & 5862 & 61 & 5.554 & 7.644 \\
\hline 23 & CIRCULAÇÃO & 8279 & 85 & 5.535 & 9.021 \\
\hline 24 & GETÚLIO & 6757 & 67 & 5.485 & 8.003 \\
\hline 25 & COLA & 7243 & 69 & 5.427 & 8.114 \\
\hline
\end{tabular}

Tabela 6: Principais colocados de marketing no corpus de português, ordenados pelo valor de Informação Mútua

Os colocados indicam marketing sendo usado como:

- Cargos dentro de uma área de atuação profissional: gerente ( de marketing), diretor, diretora, consultor, assistente.

- Tema de evento especializado: ciclo, quinzenal ("ciclo quinzenal Arena do Marketing"), palestrante, palestra. 
Há um colocado que destoa desse conjunto: "jogada", que forma "jogada de marketing”. A concordância abaixo ilustra essa colocação:

Estado, isso não passa de uma simples jogada de marketing. Como todos nós sabemos que o pa cno, sem que isso sinalize apenas uma jogada de marketing suja, é sinal de que o mundo pop da de Villeneuve à F-1 foi uma grande jogada de marketing. Campeão da Indy e com um sobren e que o petista seja envolvido numa "jogada de marketing" do governo. Debate eleito o criada pelas TVs pagas não passa de jogada de marketing para atrair publicidade. O Brasi

Essa colocação parece carregar um prosódia semântica negativa, indicada pelo léxico:

- não passa de (uma simples) jogada de marketing

- $\quad$ apenas uma jogada de marketing

- $\quad$ envolvido numa jogada de marketing.

Outras colocações semelhantes de "marketing" são as seguintes:

- $\quad$ lance de marketing (34 ocorrências)

- $\quad$ golpe de marketing (29 ocorrências).

Os principais colocados do inglês aparecem a seguir.

\begin{tabular}{|l|l|r|r|r|r|}
\hline & Colocado & \multicolumn{1}{c|}{ fc } & fnc & MI & T-Score \\
\hline 1 & SALES & 10596 & 303 & 7.539 & 17.314 \\
\hline 2 & ADVERTISING & 4495 & 89 & 7.010 & 9.361 \\
\hline 3 & MILK & 5003 & 83 & 6.754 & 9.026 \\
\hline 4 & DISTRIBUTION & 6351 & 94 & 6.590 & 9.595 \\
\hline 5 & AGGRESSIVE & 1959 & 27 & 6.487 & 5.138 \\
\hline 6 & PRODUCT & 11504 & 121 & 6.096 & 10.839 \\
\hline 7 & JOINT & 7180 & 75 & 6.086 & 8.533 \\
\hline 8 & PERSONNEL & 3393 & 33 & 5.984 & 5.654 \\
\hline 9 & PROMOTION & 3393 & 32 & 5.939 & 5.565 \\
\hline 10 & MANUFACTURINC & 4451 & 37 & 5.757 & 5.971 \\
\hline 11 & DIRECT & 11957 & 95 & 5.692 & 9.559 \\
\hline 12 & STRATEGY & 6185 & 49 & 5.688 & 6.864 \\
\hline 13 & DIRECTOR & 12435 & 98 & 5.681 & 9.707 \\
\hline 14 & PRODUCTION & 15943 & 115 & 5.552 & 10.496 \\
\hline 15 & COMPANY'S & 3886 & 28 & 5.551 & 5.179 \\
\hline
\end{tabular}




\begin{tabular}{|l|l|r|r|r|l|}
\hline 16 & GLOBAL & 3633 & 26 & 5.541 & 4.990 \\
\hline 17 & VICE & 4333 & 29 & 5.444 & 5.262 \\
\hline 18 & PRODUCTS & 10759 & 62 & 5.229 & 7.664 \\
\hline 19 & FINANCE & 7560 & 43 & 5.211 & 6.380 \\
\hline 20 & MANAGER & 13661 & 73 & 5.120 & 8.298 \\
\hline 21 & PRESIDENT & 17122 & 84 & 4.997 & 8.878 \\
\hline 22 & INTERNATIONAL & 22155 & 105 & 4.947 & 9.915 \\
\hline 23 & SELLING & 5897 & 25 & 4.786 & 4.819 \\
\hline 24 & MANAGEMENT & 21982 & 91 & 4.752 & 9.185 \\
\hline 25 & DEPARTMENT & 17299 & 57 & 4.423 & 7.198 \\
\hline
\end{tabular}

Tabela 7: Os principais colocados de marketing em inglês, ordenados pelo valor de Informação Mútua

Os padrões de marketing no inglês, a partir da tabela acima, podem ser resumidos nas seguintes categorias:

- $\quad$ Partes ou cargos de uma empresa: (marketing ) personnel, director, vice-president, manager, department

- $\quad$ Entidades que promovem marketing: Milk ( Marketing Board)

- Âmbito do marketing: International ( marketing), Global

- $\quad$ Atividades de uma empresa: (marketing ) sales and distribution, (marketing and $\sim$ ) advertising.

Também aqui há um colocado que destoa desse conjunto: aggressive ( marketing), ilustrado na concordância a seguir:

same time. But it suffered from aggressive marketing by established players such as dor has been characterized by very aggressive marketing and it is more than apparent th he majority of the population. The aggressive marketing of seats to foreign cosmonauts about glamour. Does the somewhat aggressive marketing of the Labeque lustre - tous a record breaking year by using an aggressive marketing campaign. Flying high: Thre

A concordância parece indicar a não existência de uma prosódia semântica negativa para aggressive marketing. Parece se tratar de uma atividade de marketing intensiva, feita com o intuito de iniciar, aumentar ou recuperar vendas.

Uma colocação equivalente também existe no português: "marketing agressivo", com usos semelhantes. 
Comparando os sentidos das duas palavras, podemos sugerir que marketing possui sentidos semelhantes nas duas línguas, com usos voltados à área empresarial. Seria esse, então, um caso de estrangeirismo "invasivo", ou seja, que entrou na língua portuguesa e pouco se adaptou? A resposta é não. A evidência disso vem de colocações que fogem da área empresarial. Uma delas é 'jogada de marketing', com sua prosódia semântica negativa. Não há algo diretamente semelhante em inglês com 'marketing' (talvez marketing scheme ou algum dos sentidos de bype seja aplicável nesse caso).

O termo equivalente português para marketing é "mercadologia", segundo o dicionário Aurélio. Essa palavra possui apenas 15 ocorrências no Banco de Português. Um terço dos usos da palavra mercadologia refere-se à esfera acadêmica, de cursos, conforme mostra a concordância abaixo:

inistração com concentração curricular em mercadologia, 40 para administração com propaganda e administração com ênfase em mercadologia Exame: 23 e 24 de janeiro (300 vagas), administração com ênfase em mercadologia (60) e administração com ha mercadorias e imagens ideológicas, entre mercadologia e produção cultural, vão se ós vemos... marketing... Mercadologia Um Mercadologia Dois Administração EconoMIA

Aproximadamente 25\% dos usos indicam semelhança com marketing no sentido não empresarial:

disputas eleitorais em um torneio de pura mercadologia. Duda, com Nizan Guanaes, esmo, um efeito especial. Trata-se de uma mercadologia de alto nível. Nada do que uma surra de Maradona no departamento da mercadologia. Impaciente com as idas e $v$ balho da banda, é inevitável pensar que a mercadologia da revolta está na ronda. T

Assim, parece que "mercadologia" não foi abraçada pela língua em geral e tem preferência por contextos acadêmicos e como substituto de "propaganda".

Em resumo, esta análise de marketing indica que mesmo uma palavra como ela, que mantém uma semelhança grande em relação ao seu uso na língua de partida, ainda assim adquire sentidos novos na nova língua. Isso sugere que o processo de incorporação de palavras estrangeiras estampa nessas palavras sentidos que são peculiares aos falantes da língua de chegada. 


\section{Conclusão}

Nossas questões de partida diziam respeito a duas alegações dos defensores de legislação anti-estrangeirismos, que eram a de que haveria uma invasão de palavras estrangeiras na língua portuguesa e a de que as palavras estrangeiras não se adaptariam ao português.

Em relação ao primeiro aspecto, descobrimos que as palavras em uso no inglês correspondem a cerca de 16\% do vocabulário em uso do português brasileiro. Além disso, a pesquisa revelou que as palavras advindas do inglês são de baixa freqüência. Cremos que esses achados não autorizam a aplicação do rótulo de invasão. Alguns poderiam argumentar que tal taxa de uso do vocabulário inglês é abusiva. Contudo, usando de elementos da retórica daqueles que poderiam assim pensar, cremos que dada a globalização, a influência da mídia, o poderio econômico dos EUA, e a própria "submissão" das classes dominantes do Brasil, seria de se supor que qualquer palavra do inglês entraria no português. Entretanto, mesmo depois de anos desse "ataque" interminável, o vocabulário do português do Brasil permanece independente do inglês, tanto em unidades (types) quanto em ocorrências (tokens). É neste último ponto que aparece o maior grau de independência do português, pois as palavras não inglesas são, de longe, muito mais freqüentes do que as inglesas no português.

Em relação ao segundo aspecto, observamos que palavras inglesas, mesmo quando de alta freqüência e de grafia marcadamente inglesa, adquirem usos e sentidos peculiares ao português. Ou seja, mesmo aquelas palavras que poderiam ser mais facilmente "denunciadas" como corrompendo o idioma nacional sofrem aportuguesamento.

Ambos os achados salientam a necessidade de trazer para o debate a noção de freqüência. Sem ela, a discussão se dá em termos absolutos ("a palavra $x$ do inglês está/não está no português"). Assim como em outros assuntos relativos à língua, o componente freqüencial, probabilístico é de extrema importância para entender como a língua funciona (BOD, HAY \& JANNEDY, 2003; HALLIDAY, 1991).

Os achados desta pesquisa corroboram outros estudos baseados em corpora sobre a mesma temática. Por exemplo, Berber Sardinha (BERBER SARDINHA, 2004, p. 177-184) notou que a freqüência de palavras com grafia estrangeira no português brasileiro é baixa $(0,9 \%$ do total de ocorrências) e que palavras colocadas "na lista negra", como 
delivery, light, playoffs, entre outras, possuem uma freqüência total baixa na língua. Em relação a marketing, nosso estudo vem ao encontro de Serralvo (2004), que enfocou a tradução de textos acadêmicos da própria área de marketing. Segundo esse estudo, marketing possui usos específicos no português que não são traduzíveis diretamente, mesmo em textos especializados de dentro da própria área.

Quando deixamos de lado os aspectos quantitativos da presença de unidades ortográficas nas duas línguas e nos detivemos em aspectos mais qualitativos de uso das palavras, notamos que mesmo uma palavra como marketing, com características ortográficas inglesas ("k" e "ing") e de alta freqüência, adquire sentidos freqüentes peculiares ao português, ou seja, que inexistem ou que são pouco comuns no inglês. Sendo assim, parece haver uma clara adaptação à nova língua, às preferências de seus falantes e de seu discurso. A adaptação de palavras inglesas à língua portuguesa já havia sido apontada por outros autores. Por exemplo, Garcez e Zilles (2001, p. 32) notam que outdoor, palavra de origem inglesa, passou a significar no Brasil o que nos Estados Unidos se chama de billboard.

Acreditamos ter trazido subsídios empíricos para auxiliar a discussão sobre a defesa da língua portuguesa frente ao suposto ataque do vocabulário inglês.

\section{Referências}

ALVES, I. M.; MARONEZE, B. O. Neologismos por empréstimo na imprensa brasileira contemporânea. Trabalho apresentado no $13^{\circ}$ InPLA. LAEL, PUCSP, São Paulo, 30 de abril a 3 de maio de 2003.

BAGNO, M. Cassandra, Fênix e outros mitos. In: FARACO, C. A. (Org.). Estrangeirismos - Guerras em torno da lingua. São Paulo: Parábola Editorial, 2001. p. 49-84.

BERBER SARDINHA, A. P. Calculator for WordSmith Tools Collocate Tables. Online software. http://lael.pucsp.br/corpora, 2003.

BERBER SARDINHA, A. P. Lingüística de Corpus. São Paulo: Editoria Manole, 2004.

BIBER, D.; CONRAD, S.; REPPEN, R. (Org.). Corpus Linguistics Investigating Language Structure and Use. Cambridge: Cambridge University Press, 1998. 
BOD, R.; HAY, J.; JANNEDY, S. (Org.). Probabilistic Linguistics. Cambridge, Mass: MIT Press, 2003.

CUNHA, R. B. O chute e o escorregão. Observatório da Imprensa, 27/3/2002. Disponível na Internet em http://observatorio.ultimosegundo. ig.com.br/ artigos/fd270320024.htm.

FARACO, C. A. Apresentação. In: FARACO, C. A. (Org.). Estrangeirismos Guerras em torno da língua. São Paulo: Parábola Editorial, 2001. p. 9-14. GARCEZ, P. M.; ZILLES, A. M. S. Estrangeirismos - Desejos e Ameaças. In: FARACO, C. A. (Org.). Estrangeirismos - Guerras em torno da lingua. São Paulo: Parábola Editorial, 2001. p. 15-36.

HALLIDAY, M. A. K. Corpus studies and probabilistic grammar. In: AIJMER, K.; ALTENBERG, B. (Org.). English corpus linguistics: Studies in honour ofJan Svartvik London: Longman, 1991. p. 30-43.

JORGE, F. Os deslizes e os ilogismos do Prof. John. Imprensa, v. 16, p. 59-61, 2002.

MCENERY, T.; WILSON, A. Corpus Linguistics. Edinburgh: Edinburgh University Press, 1996.

RAJAGOPALAN, K. Por uma Lingüistica crítica: linguagem, identidade e a questão ética. São Paulo: Parábola, 2003.

SCHMITZ, J. R. A Língua Portuguesa e os estrangeirismos. Diário Oficial de Leitura, v. 8, p. 4-5, 1988.

SCHMITZ, J. R. A língua portuguesa e o polêmico projeto de lei n. 1676 de 1999. Todas as Letras, v. 2, p. 64-70, 2000a.

SCHMITZ, J. R. Palavras estrangeiras e a língua portuguesa: invasão cultural ou desenvolvimento técnico-científico. Revista Caliban, v. 3, p. 42-46, 2000b.

SCHMITZ, J. R. Língua Pausterizada. Folha de S.Paulo, 6/1/1999, p. 3. Tendências/Debates.

SCHMITZ, J. R. O projeto de Lei n.1676/99 na imprensa de São Paulo. In: FARACO, C. A. (Org.). Estrangeirismos - Guerras em torno da lingua. São Paulo: Parábola Editorial, 2001b. p. 85-106.

SCHMITZ, J. R. Para que servem os dicionários? Imprensa, v. 15, p. 66-67, 2002. 
SCHMITZ, J. R. Taking linguistics seriously: on the varied dimensions of applied linguistics. Lingua, v. 114, p. 95-99, 2004.

SCOTT, M. WordSmith Tools Version 3. Oxford: Oxford University Press, 1998.

SERRALVO, G. Versão de textos acadêmicos de marketing: uma abordagem baseada em corpus. 2004. MA Thesis, LAEL, PUCSP, São Paulo.

SINCLAIR, J. Corpus, Concordance, Collocation. Oxford: Oxford University Press, 1991. 


\section{Anexos: Amostras dos resultados fornecidos pelo calculador online de estatísticas de associação}

\section{Anexo 1: Palavra "marketing" no corpus Banco de Português}

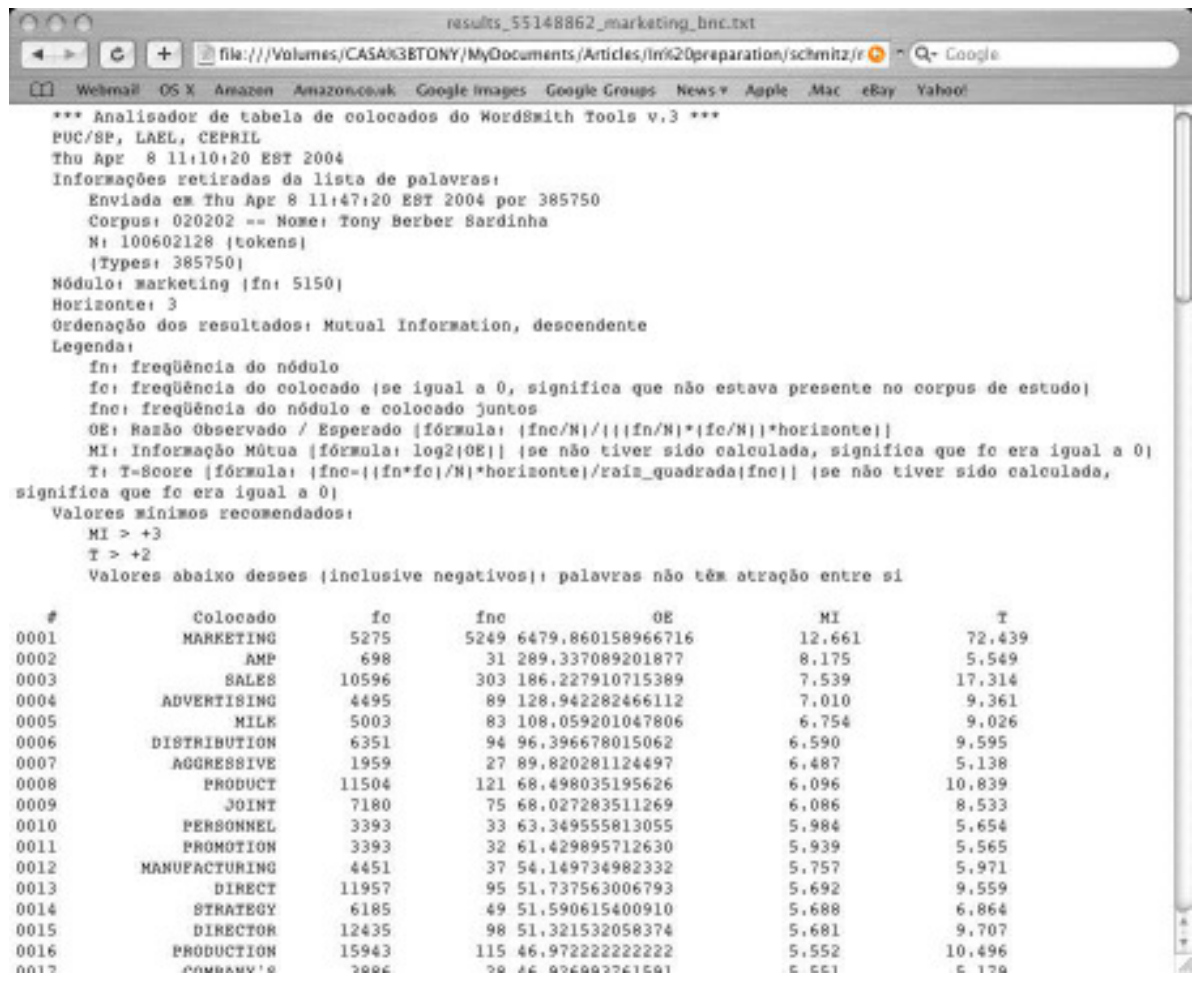




\section{Anexo 2: Palavra "marketing" no British National Corpus}

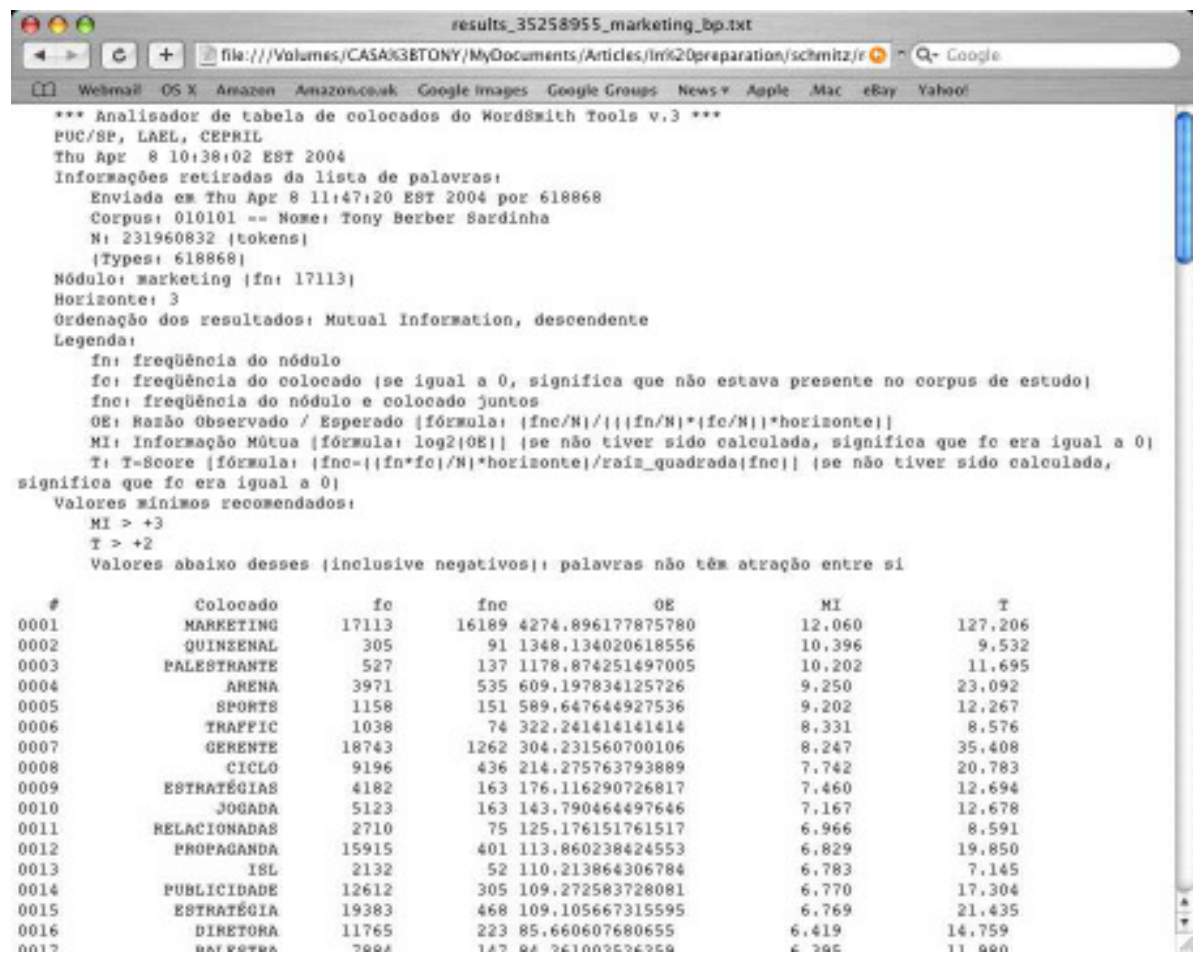

